\title{
Trends in antimicrobial resistance in Israel, 2014-2017
}

\author{
Yaakov Dickstein ${ }^{1 *}$, Elizabeth Temkin ${ }^{1}$, Michal Ish Shalom ${ }^{1}$, David Schwartz ${ }^{1}$, Yehuda Carmeli ${ }^{1,2}$ and \\ Mitchell J. Schwaber ${ }^{1,2}$
}

\begin{abstract}
We analyzed Israeli national data on antimicrobial susceptibility from bloodstream isolates collected between 2014 and 2017 and compared resistance proportions with those of Europe. The incidence of bloodstream infection (BSI) caused by most antibiotic-resistant organisms remained unchanged or decreased. An exception was increased incidence of BSI caused by third-generation cephalosporin-resistant Escherichia coli. Overall, resistance proportions were similar to those observed in southern Europe, with the exception of a lower proportion of carbapenem-resistant Klebsiella pneumoniae in Israel.
\end{abstract}

Keywords: Antibiogram, Antibiotic, Bloodstream isolate, CRE, ESBL, Israel, MRSA, Resistance, Surveillance, VRE

The Israel National Center for Infection Control (NCIC), a unit of the Ministry of Health $(\mathrm{MoH})$, has been monitoring antimicrobial resistance in selected bacteria in hospital bloodstream isolates since 2013 in the context of a national infection control program [1]. As part of the program, all acute-care hospitals in Israel are required to submit a monthly report to the NCIC with isolate-level data on all blood cultures growing seven sentinel bacteria. These data are utilized to provide monthly feedback to the hospitals on the incidence of bacteremia with resistant organisms and annually to generate institutional- and national-level antibiograms. The present report presents surveillance data on antimicrobial susceptibility testing in Israel in the period 2014-2017 and compares them with similar data from Europe.

\section{Antimicrobial resistance surveillance and reporting}

Data on antimicrobial resistance in bloodstream bacterial isolates were collected from inpatient medical records in all departments in Israel's acute-care hospitals. An isolate was considered resistant when reported by the hospital's clinical microbiology laboratory as intermediately susceptible (I) or resistant (R). For antibiotic categories

\footnotetext{
* Correspondence: Yaakov.dickstein@gmail.com; yaakov.dickstein@gmail.com ${ }^{1}$ National Center for Infection Control, Ministry of Health, Weizmann 6, 6423906 Tel Aviv, Israel

Full list of author information is available at the end of the article
}

combining more than one antibiotic agent, resistance to any agent within a class was regarded as resistance to the class.

Data on blood isolates were collated and an antibiogram prepared for selected bacteria of epidemiological importance. All hospitals contributed data on all organisms for each year. For each organism, only the first isolate per patient per year was considered. Data on colistin resistance for 2017 were not reported in accordance with the European Committee on Antimicrobial Susceptibility Testing (EUCAST) warning concerning results of susceptibility testing [2]. Data on population size were taken from the World Bank [3] while annual patient days were taken from statistics regularly distributed by the $\mathrm{MoH}$ [4-7]. Data used for comparison were taken from the 2017 report published by the European Antimicrobial Resistance Surveillance Network (EARS-Net) [8]. The Cochran-Armitage test was used to test for significant changes over time in the proportion of isolates that were resistant. We tested for significant changes over time in bloodstream infection (BSI) incidence using Poisson regression or negative binomial regression (when data were overdispersed). All calculations were performed with STATA v14.2 (StataCorp LLC, College Station, TX).

\section{Surveillance findings}

Data on the incidence of bloodstream infection (BSI) and the proportion of isolates that were resistant are 
presented in Tables 1 and 2. The following trends were observed:

- A decrease in the incidence of all Acinetobacter baumannii BSI (14.5 to 12.1 per 100,000 patientdays, $p<0.001)$ and the incidence of carbapenemresistant $A$. baumannii BSI (11.5 to 9.5 per 100,000 patient-days, $p=0.001$ ), while the proportion of $A$. baumannii isolates resistant to carbapenems remained stable at $75-80 \%$.

- An increase in the incidence of all Enterococcus faecium BSI (6.5 to 8.2 per 100,000 patient-days, $p=0.001$ ), while the incidence of vancomycinresistant Enterococcus faecium (VREf) BSI remained unchanged (1.7 to 1.6 per 100,000 patient-days, $p=$ 0.60 ). The proportion of $E$. faecium isolates resistant to vancomycin decreased (25.6 to $19.0 \%, p=0.020$ ).

- Increases in the incidence of all Escherichia coli BSI (101.6 to 110.9 per 100,000 patient-days, $p<0.001$ ), 3rd-generation cephalosporin (3GC)-resistant E. coli BSI (24.1 to 32.4 per 100,000 patient-days, $p<$ 0.001 ), and the proportion of $E$. coli isolates resistant to $3 \mathrm{GC}(29.5$ to $32.0 \%, p=0.017)$. The proportion of E. coli isolates with combined resistance to $3 \mathrm{GC}$, fluoroquinolones and aminoglycosides decreased from 10.6 to $8.3 \%(p<0.001)$; the incidence of BSI caused by these pathogens did not change significantly (8.7 to 8.2 per 100,000 patient-days $(p=0.40)$.

- No significant change in the incidence of all Klebsiella pneumoniae BSI (46.3 to 47.4 per 100,000 patient-days, $p=0.35$ ), carbapenem-resistant $K$. pneumoniae BSI (2.1 to 1.9 per 100,000 patient-days, $p=0.58$ ) or in the proportion of carbapenem-resistant isolates (4.6 to $4.0 \%, p=0.36$ ). The proportion of $K$. pneumoniae isolates with combined resistance to $3 \mathrm{GC}$, fluoroquinolones and aminoglycosides decreased from 23.7 to $19.2 \%(p=0.002)$ while the incidence of BSI caused by these strains remained unchanged ( 8.0 per 100,000 patient-days, $p=0.80$ ).

- The incidence of Pseudomonas aeruginosa BSI increased (22.2 to 25.7 per 100,000 patient-days, $p<$ 0.001 ), while the incidence of carbapenem-resistant $P$. aeruginosa remained unchanged (3.5 to 3.3 per 100,000 patient-days, $p=0.72$ ). The observed decrease in the proportion of carbapenem-resistant isolates did not achieve statistical significance (16.0 to $13.0 \%, p=0.057$ ).

- The incidence of all Staphylococcus aureus BSI increased, from 42.4 to 47.1 per 100,000 patient-days $(p<0.001)$, driven by the rising incidence of methicillin-susceptible $S$. aureus BSI (26.2 to 32.7 per 100,000 patient-days, $p<0.001$ ). The incidence of BSI caused by methicillin-resistant $S$. aureus (MRSA) declined from 16.2 to 14.4 per 100,000 patient-days $(p=0.04)$. The percentage of methicillin-resistant S.aureus isolates decreased from 38.2 to $30.6 \%(p<0.001)$.

- The combined incidence of A. baumannii, E. faecium, K. pneumoniae and $P$. aeruginosa BSI remained unchanged (89.5 to 93.4 per 100,000 patient-days, $p=0.14$ ), as did the combined incidence of VREf and carbapenem-resistant A. baumannii, $K$. pneumoniae and $P$. aeruginosa (18.8 to 16.3 per 100,000 patient-days, $p=0.090$ ).

In general, resistance proportions were similar to those reported by countries in southern Europe (Italy and Greece), with the exception of carbapenem-resistant and combined 3GC-, fluoroquinolone- and aminoglycosideresistant $K$. pneumoniae, for which the proportions were lower in Israel $(4.0 \% / 19.2 \%$, respectively, in 2017 , vs $29.7 / 31.6 \% \%$ in Italy and $64.7 / 47.9 \% \%$ in Greece) and carbapenem-resistant $P$. aeruginosa, for which the proportion was lower in Israel (13.0\%) than in Greece (39.3\%) [8].

\section{Discussion}

In Israel between 2014 and 2017, the incidence of BSI caused by most antibiotic-resistant organisms remained unchanged or decreased. An exception was the incidence of BSI caused by 3GC-resistant $E$. coli, which increased. Overall, resistance proportions were similar to those observed in southern Europe, with the exception of carbapenem-resistant $K$. pneumoniae, for which the resistance proportion in Israel was markedly lower.

Following an outbreak of carbapenem-resistant Enterobacteriaceae (CRE) in Israeli health-care facilities in 2006, a national intervention was implemented to identify carriers of CRE and prevent ongoing transmission [9]. The intervention succeeded in reducing the incidence of CRE acquisition and subsequently overall CRE prevalence in Israel [10-12]. This success catalyzed a broader nationwide infection control (IC) program which, apart from surveillance of antimicrobial susceptibility, included the establishment of a central reference laboratory, enhancement of IC programs within individual healthcare institutions and the creation of a national antibiotic stewardship program [1]. Thus, the trends toward decreasing incidence of many antibiotic-resistant organisms reported here occurred in the context of an intensive, nationally-coordinated IC effort which included the use of antimicrobial susceptibility data to plan and prioritize focused interventions where warranted.

This report has a number of limitations. First, there is no national standard for reporting of antimicrobial susceptibility. Although most microbiology laboratories in Israel employ Clinical and Laboratory Standards Institute (CLSI) breakpoints, this is not mandatory. Thus, it is 
Table 1 Percentage of Resistant Isolates, Israel, 2014-2017

\begin{tabular}{|c|c|c|c|c|c|c|c|c|c|c|c|c|c|c|c|c|c|c|c|c|c|c|c|c|}
\hline 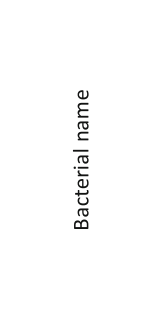 & 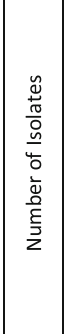 & 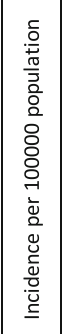 & 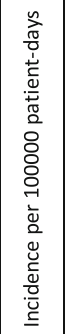 & 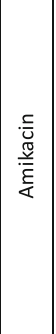 & 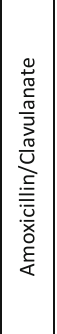 & 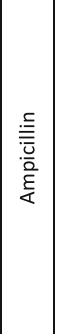 & 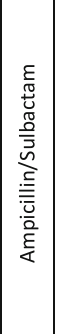 & 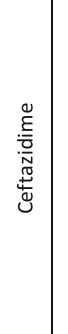 & 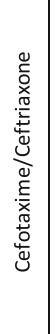 & 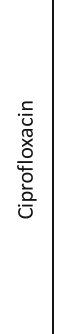 & 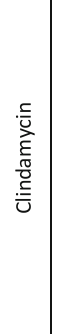 & 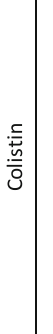 & 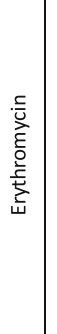 & 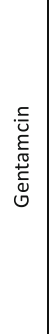 & 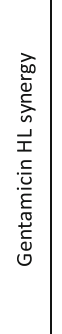 & 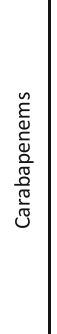 & 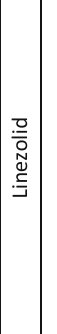 & 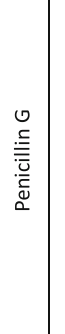 & 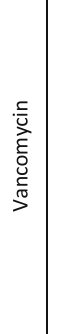 & 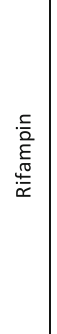 & 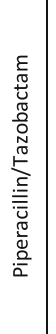 & 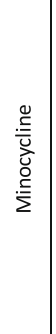 & 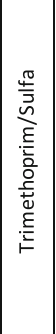 & 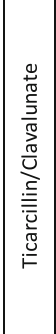 \\
\hline \multicolumn{25}{|c|}{2014} \\
\hline A. baumannii & 696 & 8.5 & 14.5 & 75.2 & & & $67.4 \mathrm{~s}$ & \begin{tabular}{|l|l|}
90.9 & 9 \\
\end{tabular} & 97.8 & 91.1 & & 0.4 & & 81.4 & & 79.6 & & & & & 90.3 & 25.7 & 75.2 & 87.3 \\
\hline E. faecalis & 1171 & 14.3 & 24.4 & & & 3.4 & & & & & & & 81.2 & & 59.4 & & \begin{tabular}{|l|l|}
0.3 & 1 \\
\end{tabular} & 11.2 & 0.3 & & & & & \\
\hline E. faecium & 314 & 3.8 & 6.5 & & & 85.3 & & & & & & & 93.8 & & 48.2 & & \begin{tabular}{|l|l|}
1.3 & 8 \\
\end{tabular} & 87.02 & 25.6 & & & & & \\
\hline E. coli & 4880 & 59.4 & 101.6 & 1.6 & 38.5 & 72.6 & \begin{tabular}{|l|l}
50.1 & 2 \\
\end{tabular} & \begin{tabular}{|l|l|}
29.5 & 2 \\
\end{tabular} & 29.9 & 36.4 & & 0.0 & & 19.1 & & 0.3 & & & & & 7.3 & & 42.6 & 41.1 \\
\hline K. pneumoniae & 2223 & 27.1 & 46.3 & 7.6 & 51.3 & & 63.45 & \begin{tabular}{|l|l}
54.0 & 5 \\
\end{tabular} & 53.2 & 44.5 & & 3.2 & & 34.6 & & 4.6 & & & & & 28.4 & & 52.4 & 62.5 \\
\hline S. aureus & 2037 & 24.8 & 42.4 & & & & & & & 38.4 & 42.9 & & 41.7 & 19.5 & & & 0.0 & & 0.0 & 0.6 & & 0.1 & 1.9 & \\
\hline MRSA & 779 & 9.5 & 16.2 & & & & & & & 90.9 & 76.0 & & 72.9 & 42.2 & & & 0.0 & & 0.0 & 1.2 & & 0.3 & 2.3 & \\
\hline MSSA & 1258 & 15.3 & 26.2 & & & & & & & 5.9 & 22.4 & & 22.4 & 5.5 & & & 0.0 & & 0.0 & 0.3 & & 0.0 & 1.7 & \\
\hline P. aeruginosa & 1068 & 13.0 & 22.2 & 3.6 & & & & 12.0 & & 16.7 & & 0.5 & & 10.9 & & 16.0 & & & & & 8.4 & & & 54.3 \\
\hline \multicolumn{25}{|c|}{2015} \\
\hline A. baumannii & 739 & 8.8 & 15.1 & 66.1 & & & \begin{tabular}{|l|l|}
67.3 & 8 \\
\end{tabular} & \begin{tabular}{|l|l}
86.5 & 9 \\
\end{tabular} & 97.2 & 86.8 & & 0.6 & & 77.1 & & 79.3 & & & & & 86.7 & 22.4 & 74.3 & 75.1 \\
\hline E. faecalis & 1062 & 12.7 & 27.1 & & & 3.5 & & & & & & & 86.5 & & 55.7 & & 0.2 & $9.7 \quad 6$ & 0.2 & & & & & \\
\hline E. faecium & 327 & 3.9 & 6.7 & & & 78.4 & & & & & & & 95.7 & & 47.9 & & 1.17 & \begin{tabular}{l|l}
79.9 & 2 \\
\end{tabular} & 20.8 & & & & & \\
\hline E. coli & 5287 & 63.1 & 108.2 & 1.7 & 37.7 & 71.5 & 54.13 & \begin{tabular}{|l|l|}
32.0 & 3 \\
\end{tabular} & 32.0 & 37.5 & & 0.0 & & 18.2 & & 0.4 & & & & & 8.1 & & 42.6 & 46.5 \\
\hline K. pneumoniae & 2069 & 24.7 & 42.3 & 6.7 & 47.8 & & \begin{tabular}{|l|l}
60.3 & 5 \\
\end{tabular} & \begin{tabular}{|l|l}
50.6 & 5 \\
\end{tabular} & 50.3 & 41.0 & & 0.8 & & 33.0 & & 3.7 & & & & & 26.7 & & 52.0 & 62.3 \\
\hline S. aureus & 2127 & 25.4 & 43.6 & & & & & & & 34.7 & 39.4 & & 41.6 & 16.5 & & & 0.0 & & 0.0 & 0.9 & & 0.0 & 1.3 & \\
\hline MRSA & 746 & \begin{tabular}{|l|}
8.9 \\
\end{tabular} & 15.3 & & & & & & & 89.7 & 73.5 & & 76.03 & 37.8 & & & 0.0 & & 0.0 & 1.7 & & 0.0 & 2.2 & \\
\hline MSSA & 1381 & 16.5 & 28.3 & & & & & & & 5.1 & 21.0 & & 23.0 & 5.1 & & & 0.0 & & 0.0 & 0.4 & 0.0 & 0.0 & 0.8 & \\
\hline P. aeruginosa & 1217 & 14.5 & 24.9 & 4.7 & & & & 10.9 & & 18.4 & & 0.6 & & 11.1 & & 14.3 & & & & & 9.4 & & & 55.4 \\
\hline \multicolumn{25}{|c|}{2016} \\
\hline A. baumannii & 632 & 7.4 & 12.8 & 66.3 & & & \begin{tabular}{|l|l|}
64.7 & $\varepsilon$ \\
\end{tabular} & \begin{tabular}{|l|l|}
83.9 & 9 \\
\end{tabular} & 96.0 & 84.6 & & 0.8 & & 75.3 & & 74.8 & & & & & 83.9 & 19.9 & 74.5 & 70.2 \\
\hline E. faecalis & 1175 & 13.7 & 23.9 & & & 1.8 & & & & & & & 89.2 & & 48.0 & & 0.0 & 5.4 & 0.0 & & & & & \\
\hline E. faecium & 370 & 4.3 & 7.5 & & & 77.9 & & & & & & & 92.5 & & 40.1 & & \begin{tabular}{|l|l|}
1.1 & 8 \\
\end{tabular} & 84.01 & 16.8 & & & & & \\
\hline E. coli & 5442 & 63.7 & 110.5 & 2.0 & 37.4 & 63.3 & 52.03 & \begin{tabular}{|l|l|}
32.2 & 3 \\
\end{tabular} & 32.7 & 35.9 & & 0.2 & & 16.7 & & 0.3 & & & & & 7.9 & & 40.2 & 35.1 \\
\hline K. pneumoniae & 2291 & 26.8 & 46.5 & 6.5 & 47.2 & & \begin{tabular}{|l|l}
58.7 & 5 \\
\end{tabular} & \begin{tabular}{|l|l}
51.5 & 5 \\
\end{tabular} & 51.5 & 38.8 & & 1.8 & & 33.7 & & 3.8 & & & & & 27.5 & & 51.3 & 59.0 \\
\hline S. aureus & 2283 & 26.7 & 46.3 & & & & & & & 32.3 & 40.6 & & \begin{tabular}{l|l}
41.6 \\
\end{tabular} & 14.1 & & & 0.0 & & 0.0 & 1.2 & & 0.1 & 2.4 & \\
\hline MRSA & 769 & 9.0 & 15.6 & & & & & & & 88.2 & 68.8 & & 70.0 & 33.7 & & & 0.0 & & 0.0 & 2.1 & & 0.3 & 3.9 & \\
\hline MSSA & 1514 & 17.7 & 30.7 & & & & & & & 3.9 & 26.3 & & 27.2 & 4.1 & & & 0.0 & & 0.0 & 0.7 & & 0.0 & 1.6 & \\
\hline P. aeruginosa & 1283 & 15.0 & 26.0 & 3.6 & & & & 11.1 & & 17.6 & & 0.4 & & 11.3 & & 14.5 & & & & & 9.4 & & & 55.6 \\
\hline \multicolumn{25}{|c|}{2017} \\
\hline A. baumannii & 595 & 6.8 & 12.1 & 65 & & & 67 & 83 & 97 & 83 & & ND & & 72 & & 78 & & & & & 83 & 22 & 70 & 23 \\
\hline E. faecalis & 1111 & 12.8 & 22.7 & & & 2.1 & & & & & & & 86 & & 49 & & 0.0 & 8 & 0.1 & & & & & \\
\hline E. faecium & 404 & \begin{tabular}{|l|}
4.6 \\
\end{tabular} & \begin{tabular}{|l|}
8.2 \\
\end{tabular} & & & 84 & & & & & & & 95 & & 45 & & \begin{tabular}{|l|l}
0.0 \\
\end{tabular} & 92 & 19 & & & & & \\
\hline E. coli & 5440 & \begin{tabular}{|l|}
62.4 \\
\end{tabular} & 110.9 & 2.1 & 37 & 71 & 52 & 31 & 32 & 35 & & ND & & 16 & & 0.3 & & & & & 9 & & 38 & 11 \\
\hline K. pneumoniae & 2323 & 26.7 & 47.4 & 6 & 43 & & 60 & 50 & 51 & 37 & & ND & & 29 & & 4 & & & & & 25 & & 52 & 41 \\
\hline S. aureus & 2307 & 26.5 & 47.1 & & & & & & & 30.3 & 39.8 & & 40.8 & 13.5 & & & 0.0 & & 0.0 & 1.2 & & 0.0 & 1.7 & \\
\hline MRSA & 705 & 8.1 & 14.4 & & & & & & & 88 & 71 & & 70 & 35 & & & 0.2 & & 0.0 & 3 & & 0.0 & 3 & \\
\hline MSSA & 1602 & 18.4 & 32.7 & & & & & & & 5 & 26 & & 28 & 4 & & & 0.0 & & 0.0 & 0.4 & & 0.1 & 1.2 & \\
\hline P. aeruginosa & 1262 & 14.5 & 25.7 & 4 & & & & 13 & & 17 & & $\mathrm{ND}$ & & 13 & & 13 & & & & & 13 & & & 60 \\
\hline
\end{tabular}

HL High level, MRSA methicillin-resistant S. aureus, MSSA methicillin-susceptible S. aureus, ND No data, Sulfa Sulfamethoxazole

possible that for certain antibiotic categories for which CLSI breakpoints are higher than those issued by the European Committee on Antimicrobial Susceptibility Testing (EUCAST), levels of antimicrobial resistance as we reported are lower than they would be utilizing
EUCAST criteria. However, given that differences where present tend to be relatively small (i.e. one dilution), we believe that the general comparison with EARS-Net data remains valid [13]. Second, we do not differentiate resistance levels between community-acquired and hospital- 
Table 2 Percentage and Incidence of Combined Resistance Phenotypes, Israel, 2014-2017

\begin{tabular}{|c|c|c|c|c|c|c|c|c|}
\hline \multirow[b]{2}{*}{ Bacterial name } & \multicolumn{2}{|l|}{2014} & \multicolumn{2}{|l|}{2015} & \multicolumn{2}{|l|}{2016} & \multicolumn{2}{|l|}{2017} \\
\hline & $\begin{array}{l}\text { Percentage } \\
\text { of resistant } \\
\text { isolates }\end{array}$ & $\begin{array}{l}\text { Incidence } \\
\text { per } 100,000 \\
\text { patient-days }\end{array}$ & $\begin{array}{l}\text { Percentage } \\
\text { of resistant } \\
\text { isolates }\end{array}$ & $\begin{array}{l}\text { Incidence } \\
\text { per } 100,000 \\
\text { patient-days }\end{array}$ & $\begin{array}{l}\text { Percentage } \\
\text { of resistant } \\
\text { isolates }\end{array}$ & $\begin{array}{l}\text { Incidence } \\
\text { per } 100,000 \\
\text { patient-days }\end{array}$ & $\begin{array}{l}\text { Percentage of } \\
\text { resistant isolates }\end{array}$ & $\begin{array}{l}\text { Incidence } \\
\text { per } 100,000 \\
\text { patient-days }\end{array}$ \\
\hline A. baumannii Carb+FQ + AG & 73.2 & 8.4 & 74.2 & 9.3 & 72.2 & 7.8 & 70.1 & 7.2 \\
\hline E. coli 3GC & 29.5 & 24.1 & 32.0 & 30.2 & 32.4 & 32.3 & 32.0 & 32.4 \\
\hline E. coli $3 G C+F Q+A G$ & 10.6 & 8.7 & 10.3 & 9.7 & 9.3 & 9.1 & 8.3 & 8.2 \\
\hline K. pneumoniae 3GC + FQ + AG & 23.7 & 8.0 & 20.8 & 7.6 & 20.7 & 8.3 & 19.2 & 8.0 \\
\hline K. pneumoniae Carb+Col & 1.8 & 0.2 & 0.6 & 0.0 & 0.4 & 0.0 & ND & ND \\
\hline
\end{tabular}

AG Aminoglycoside-resistant, Carb Carbapenem-resistant, Col Colistin-resistant, FQ Fluoroquinolone-resistant, 3GC 3rd-generation cephalosporin-resistant

acquired/health care-associated infections. Thus, is it likely that for nosocomial infections, the resistance levels are higher than what we have reported.

As noted above, the success of the intervention for CRE, which saw the proportion of carbapenem-resistant K. pneumoniae bloodstream isolates decline from $22 \%$ in 2007 to $4 \%$ one decade later [1], can explain the difference in the proportion of carbapenem-resistant $K$. pneumoniae BSI isolates between Israel and southern Europe. In contrast, both our data and previous Israeli studies indicate a steady increase in the incidence of bloodstream infections due to extended-spectrum $\beta$-lactamase (ESBL)-producing Enterobacteriaceae and the proportion of Enterobacteriaceae blood isolates producing ESBL during the same period [14-16]. The use of targeted control efforts for CRE has been cited as one factor explaining the limited spread of CRE in the United States as compared with ESBL-producing bacteria [17].

An important difference in the epidemiology of ESBL-producing and carbapenem-resistant Gram-negative bacteria is the role of asymptomatic carriers in the community. Carbapenem-resistance is primarily nosocomial, with little to no transmission in community settings reported outside of eastern Asia [18]. ESBL-producing Enterobacteriaceae, however, have spread to colonize healthy community dwellers with no or minimal healthcare contact [19]. These carriers serve as a major reservoir for infections with ESBL-producing bacteria in hospitals as well, implying that interventions which concentrate principally on healthcare settings may have limited success in controlling the spread of these organisms $[20,21]$. In Israel, where interventions have focused on healthcare facilities, the combined incidence of BSI with typically hospital-acquired antibioticresistant organisms decreased at the same time that incidence of ESBL-producing $E$. coli BSI rose. Ongoing efforts are necessary to further inhibit the spread of resistant organisms, including the development of interventions aimed at community settings.

\section{Abbreviations}

3GC: 3rd-generation cephalosporin; BSI: Bloodstream infection; CLSI: Clinical and Laboratory Standards Institute; CRE: Carbapenem-resistant Enterobacteriaceae;
EARS-Net: European Antimicrobial Resistance Surveillance Network; ESBL: Extended-spectrum $\beta$-lactamase; EUCAST: European Committee on Antimicrobial Susceptibility Testing; I: Intermediate susceptibility; IC: Infection control; MoH: Ministry of Health; MRSA: Methicillin-resistant Staphylococcus aureus; NCIC: National Center for Infection Control; R: Resistant; VREf: Vancomycin-resistant Enterococcus faecium

\section{Acknowledgements}

We thank all of the healthcare institutions and personnel who contributed to the antimicrobial resistance data summarized and analyzed in this report.

\section{Funding}

The work on this article was performed as part of the work of the National Center for Infection Control of the Israel Ministry of Health.

\section{Availability of data and materials}

The datasets generated and/or analysed during the current study are available in the "Periodic Reports" repository, https://www.health.gov.il/ UnitsOffice/HD/InfectionControl/Pages/Periodic_reports.aspx

\section{Authors' contributions}

YD analyzed and interpreted the aggregated data and wrote the article. ET analyzed and interpreted the aggregated data. MIS aggregated and analyzed the raw microbiological data. DS aggregated and interpreted the raw microbiological data. YC oversaw the collection, aggregation, and interpretation of the data and jointly conceived the idea for the report. MJS oversaw the collection, aggregation, and interpretation of the data and jointly conceived the idea for the report. All authors read and approved the final manuscript.

\section{Ethics approval and consent to participate}

Publication was approved by the Israel Ministry of Health. As per MoH policy, the article, which reports national aggregated data, publically available on the $\mathrm{MoH}$ website, was not subject to ethics committee approval.

\section{Consent for publication}

Not applicable.

\section{Competing interests}

The authors declare that they have no competing interests.

\section{Publisher's Note}

Springer Nature remains neutral with regard to jurisdictional claims in published maps and institutional affiliations.

\section{Author details}

${ }^{1}$ National Center for Infection Control, Ministry of Health, Weizmann 6, 6423906 Tel Aviv, Israel. ${ }^{2}$ Sackler Faculty of Medicine, Tel Aviv University, Kalechkin 35, 6997801 Tel Aviv, Israel. 
Received: 22 January 2019 Accepted: 8 May 2019

Published online: 04 June 2019

\section{References}

1. Schwaber MJ, Carmeli Y. The impact of a carbapenem-resistant Enterobacteriaceae outbreak on facilitating development of a national infrastructure for infection control in Israel. Clin Infect Dis. 2017:65:2144-9.

2. European Committee on Antimicrobial Susceptibility Testing (EUCAST) EUCAST warnings concerning antimicrobial susceptibility testing products or procedures. Available from: http://www.eucast.org/ast_of_bacteria/ warnings/\#c13111. Accessed 6 May 2019.

3. The World Bank Group. Available from: https://www.worldbank.org/. Accessed 6 May 2019.

4. Israeli Ministry of Health. [In-patient institutions and units for day hospitalization in Israel 2014]. Available from: https://www.health.gov.il/ publicationsfiles/mosadot2014_p2.pdf. Accessed 6 May 2019.

5. Israeli Ministry of Health. [In-patient institutions and units for day hospitalization in Israel 2015]. Available from: https://www.health.gov.il/ publicationsfiles/mosadot2015_p2.pdf. Accessed 6 May 2019.

6. Israeli Ministry of Health. [In-patient institutions and units for day hospitalization in Israel 2016]. Available from: https://www.health.gov.il/ publicationsfiles/mosadot2016_p2.pdf. Accessed 6 May 2019.

7. Israeli Ministry of Health. [In-patient institutions and units for day hospitalization in Israel 2017]. Available from: https://www.health.gov.il/ publicationsfiles/mosadot2017_p2.pdf. Accessed 6 May 2019.

8. European Centre for Disease Prevention and Control. Surveillance of antimicrobial resistance in Europe - Annual report of the European Antimicrobial Resistance Surveillance Network (EARS-Net) 2017. Stockholm: ECDC; 2018. Available from: https://ecdc.europa.eu/sites/portal/files/ documents/AMR-surveillance-EARS-Net-2017-updated-dec-18.pdf. Accessed 6 May 2019

9. Schwaber MJ, Lev B, Israeli A, Solter E, Smollan G, Rubinovitch B, et al. Containment of a country-wide outbreak of carbapenem-resistant Klebsiella pneumoniae in Israeli hospitals via a nationally implemented intervention. Clin Infect Dis. 2011:52:848-55.

10. Schwaber MJ, Carmeli Y. An ongoing national intervention to contain the spread of carbapenem-resistant enterobacteriaceae. Clin Infect Dis. 2014; 58(5):697-703.

11. Ben-David D, Masarwa S, Adler A, Mishali H, Carmeli Y, Schwaber MJ. A national intervention to prevent the spread of carbapenem-resistant Enterobacteriaceae in Israeli post-acute care hospitals. Infect Control Hosp Epidemiol. 2014:35(7):802-9.

12. Ben-David D, Masarwa S, Fallach N, Temkin E, Solter E, Carmeli Y, et al Success of a national intervention in controlling carbapenem-resistant Enterobacteriaceae in Israel's long-term care facilities. Clin Infect Dis. 2019;68(6):964-71.

13. Kassim A, Omuse G, Premji Z, Revathi G. Comparison of clinical laboratory standards institute and European committee on antimicrobial susceptibility testing guidelines for the interpretation of antibiotic susceptibility at a university teaching hospital in Nairobi, Kenya: a cross-sectional study. Ann Clin Microbiol Antimicrob. 2016;15:21.

14. Ben-Ami R, Schwaber MJ, Navon-Venezia S, Schwartz D, Giladi M, Chmelnitsky I, et al. Influx of extended-spectrum beta-lactamase-producing enterobacteriaceae into the hospital. Clin Infect Dis. 2006;42:925-34.

15. Chazan B, Raz R, Teitler N, Nitzan O, Edelstein H, Colodner R. Epidemiology and susceptibility to antimicrobials in community, hospital and long-term care facility bacteremia in northern Israel: a 6 year surveillance. Isr Med Assoc J. 2009;11:592-7.

16. Karfunkel D, Carmeli Y, Chmelnitsky I, Kotlovsky T, Navon-Venezia S. The emergence and dissemination of CTX-M-producing Escherichia coli sequence type 131 causing community-onset bacteremia in Israel. Eur J Clin Microbiol Infect Dis. 2013;32:513-21.

17. Woodworth KR, Walters MS, Weiner LM, Edwards J, Brown AC, Huang JY, et al. Vital signs: containment of novel multidrug-resistant organisms and resistance mechanisms - United States, 2006-2017. MMWR Morb Mortal Wkly Rep. 2018;67:396-401.

18. Kelly AM, Mathema B, Larson EL. Carbapenem-resistant Enterobacteriaceae in the community: a scoping review. Int J Antimicrob Agents. 2017:50:127-34.

19. Doi Y, Park YS, Rivera Jl, Adams-Haduch JM, Hingwe A, Sordillo EM, et al Community-associated extended-spectrum beta-lactamase-producing Escherichia coli infection in the United States. Clin Infect Dis. 2013;56:641-8.
20. Karanika S, Karantanos T, Arvanitis M, Grigoras C, Mylonakis E. Fecal colonization with extended-spectrum beta-lactamase-producing Enterobacteriaceae and risk factors among healthy individuals: a systematic review and metaanalysis. Clin Infect Dis. 2016:63:310-8.

21. Tschudin-Sutter S, Lucet JC, Mutters NT, Tacconelli E, Zahar JR, Harbarth S. Contact precautions for preventing nosocomial transmission of extendedspectrum beta lactamase-producing Escherichia coli: a point/counterpoint review. Clin Infect Dis. 2017;65:342-7.

Ready to submit your research? Choose BMC and benefit from:

- fast, convenient online submission

- thorough peer review by experienced researchers in your field

- rapid publication on acceptance

- support for research data, including large and complex data types

- gold Open Access which fosters wider collaboration and increased citations

- maximum visibility for your research: over $100 \mathrm{M}$ website views per year

At BMC, research is always in progress.

Learn more biomedcentral.com/submissions 